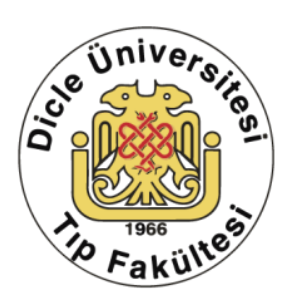

\title{
Güneydoğu Anadolu Bölgesindeki Üçüncü Basamak Gastroenteroloji Kliniğinin Toksik Hepatit Deneyimi
}

\author{
Feyzullah Uçmak' ${ }^{1}$, Elif Tuğba Tuncel², Hüseyin Kaçmaz ${ }^{3}$, Berat Ebik', Muhsin Kaya ${ }^{5}$ \\ 1 Department of Gastroenterology, Dicle University School of Medicine, Diyarbakir, Turkey ORCID: 0000-0002-2677-3971 \\ 2 Department of Gastroenterology, Dicle University School of Medicine, Diyarbakir, Turkey ORCID: 0000-0001-9547-9445 \\ 3 Department of Gastroenterology, Dicle University School of Medicine, Diyarbakir, Turkey ORCID: 0000-0001-6788-3459 \\ 4 Department of Gastroenterology, Dicle University School of Medicine, Diyarbakir, Turkey ORCID: 0000-0002-0012-2505 \\ 5 Department of Gastroenterology, Dicle University School of Medicine, Diyarbakir, Turkey ORCID: 0000-0002-7178-360X
}

Geliş: 31.10.2017, Revizyon: 16.03.2018, Kabul Tarihi: 02.04.2018

Özet

Amaç: Toksik hepatit birçok ilaç ve bitkisel ürünün alınmasıyla ortaya çıkan klinik tablodur. Çok sayıda ilaç değişik mekanizmalarla toksik hepatite neden olmaktadır. Hastalığın görülme sıklığı ve sebepleri bölgesel farklılıklar gösterebilmektedir. Çalışmadaki amacımız kliniğimize başvuran toksik hepatitli olguların demografik, klinik ve laboratuar özelliklerini sunmaktır.

Yöntemler: Ağustos 2014-Haziran 2016 tarihleri arasında kliniğimize anormal karaciğer fonksiyon testleri nedeniyle yatırılan, klinik ve laboratuar değerlendirme sonrası TH tanısı konulan hastalar alındı. Hastaların demografik özellikleri, toksik hepatitin muhtemel etiyolojisi, klinik özellikleri, biyokimya ve tam kan değerleri, klinik seyirleri kaydedildi.

Bulgular: Çalışmaya yaş ortalaması 41.4ะ16.8 olan 56 (34 kadın) hasta alındı. Hastaların 31 (\%55.6)'inde ilaçlar, 11 (\%20.4)'inde bitkisel maddeler, $6(\% 9,3)$ 'ında narkotik madde ve $8(\% 14,8)$ 'inde bitkisel madde, ilaç ve narkotik kullanımına bağlı toksik hepatit geliştiği saptandı. İlaçlar içinde en çok antibiyotik (birinci sırada amoksisilin+ klavulanik asit) ve non-steroid anti inflamatuvar ilaç (birinci sırada diklofenak sodyum) kullanımı hikayesi saptandı. Bitkisel madde kullanımı olan hastalarda en sık meryem otu, lavanta çayı ve atom çayı kullanım hikayesi mevcuttu. Narkotik madde olarak en sık ekstazi (5 hasta) kullanımı saptandı. Otuz yaş altı (RR:1.545, p<0.001) ve erkek cinsiyet (RR:11.0, p=0.013) narkotik madde kullanımı için risk faktörü olarak saptan dı.

Sonuç: Bölgemizde ilaç ve bitkisel madde kullanımına bağlı gelișen TH anormal karaciğer fonksiyon testlerinin önemli bir sebebi olarak dikkate alınmalıdır. Özellikle genç erkeklerde narkotik kullanımı toksik hepatit etiyolojisinde önemli yer tutmaktadır.

Anahtar Kelimeler: Toksik hepatit, ilaca bağlı karaciğer hasarı, bitkisel ürünler, N-Metil-3,4-metilendioksiamfetamin, ekstazi.

DOI: $10.5798 /$ dicletip. 425003

Yazışma Adresi / Correspondence: Feyzullah Ucmak, Dicle Üniversitesi Tıp Fakültesi, Gastroenteroloji Kliniği 21100, Sur/Diyarbakır, Türkiye e-mail: $\underline{\text { ucmakfeyz@gmail.com }}$ 


\title{
Toxic hepatitis experience of the tertiary gastroenterological clinics in the Southeastern Anatolia
}

\begin{abstract}
Objective: Toxic hepatitis is a clinical picture caused by the intake of many drugs and herbal products. Numerous drugs lead to toxic hepatitis through a variety of mechanisms. The prevalence and causes of the disease vary by regions. This study aims at presenting demographic, clinical and laboratory characteristics of toxic hepatitis cases that sought medical care at our clinics.

Methods: This study comprises patients hospitalized at our clinics due to abnormal liver function tests and diagnosed with toxic hepatitis as a result of clinical and laboratory examinations between August 2014 and June 2016. The demographic characteristics of the patients, the potential etiology of the toxic hepatitis, clinical characteristics, biochemical and complete blood count results and the clinical course were recorded.

Results: Fifty-six patients ( 34 women) with a mean age of $41.4 \pm 16.8$ were included in this study. Toxic hepatitis was detected in 31 patients (55.6\%) for use of drugs, 11 patients (20.4\%) of herbal products, 6 patients (9.3\%) of narcotic substances and 8 patients (14.8\%) of herbal substances, drugs and narcotics. The most common drugs of all were antibiotics (amoxicillin + clavulanic acid ranking atop) and non-steroidal anti-inflammatory drugs (diclofenac sodium ranking atop). Patients with the use of herbal products commonly had a history of use for milk thistle, lavender tea and atom tea. The most common narcotic substance turned out to be ecstasy ( 5 patients). The age under thirty (RR: $1.545, p<0.001$ ) and the male gender (RR: 11.0, $p=0.013$ ) were determined as risk factors for the use of narcotics.

Conclusion: Caused by the use of drugs and herbal products across the region, TH should be taken into consideration as a major cause of abnormal liver function tests. The use of narcotics for young men in particular plays a large role in the etiology of toxic hepatitis.
\end{abstract}

Keywords: Toxic hepatitis, drug-induced liver injury, herbal products, N-Methyl-3,4-methylenedioxyamphetamine

\section{GİRIŞ}

Vücudun kendi metabolizmasının son ürünlerinin yanısıra dışarıdan alınan maddelerin (ksenobi-yotik) metabolizmasindan sorumlu temel organ karaciğerdir ${ }^{1}$. $\mathrm{Bu}$ nedenle ilaç ve bitkisel maddeleri içeren ksenobiyotiklere bağlı karaciğer hasarlanması bunların önde gelen toksik etkilerinden biridir ${ }^{1,2}$. Hem ilaçlara (drug-induced) hem de bitkisel maddelere (herbal-induced) bağlı bu karaciğer hasarlanması toksik hepatit (TH) kliniğinin gelişmesine neden olur. Toksik hepatit çoğunlukla ilaçların önerilen dozlarında kullanırken (doz aşımı olmadan) idiyosenkratik mekaniz-malar sonucunda gelişmektedir ${ }^{3}$. İlaç geliştirme çabalarının yarıda kalmasının yanısıra kullanımda olan ilaçların da piyasadan geri çekilmesinin en önemli nedeni olması münasabetiyle hem hekimleri hem hastaları hem de ilaç sanayini etkileyen önemli bir durumdur. İlaçlara bağlı karaciğer hasarının yıllık insidansı 10-15/10.000-100.000 kişi arasında olduğu tahmin edilmektedir ${ }^{4,5}$. Amerika Birleşik Devletler'inde akut hepatit vakalarının yaklaşık \%10'unun, akut karaciğer yetmezliği vakalarının ise yarısından fazlasının sebebidir6,7. Toksik hepatit asemptomatik karaciğer fonksiyon testlerinin yüksekliğinden akut/subakut karaciğer yetmezliğine değișen bir çok klinik tablo ile karşımıza çıkabilir5.

Hastalığın görülme sıklığı ve sebepleri bölgesel farklılıklar gösterebilmektedir. Çalışmadaki amacımız kliniğimize başvuran TH'li olguların demografik, klinik ve laboratuar özelliklerini sunmaktır. 


\section{YÖNTEMLER}

$\mathrm{Bu}$ çalışmaya Ağustos 2014-Haziran 2016 tarihleri arasında kliniğimize anormal karaciğer fonksiyon testleri nedeniyle yatırılan, klinik ve laboratuar değerlendirme sonrası TH tanısı konulan hastalar alındı. Çalışmaya alınma kriterleri; alanin veya asetat aminotransferaz (ALT veya AST), alkalen fosfataz (ALP) herhangi bir seviyedeki yüksekliğiyle birlikte sarllı (total bilurubin> $2.5 \mathrm{mg} / \mathrm{dl}$ ) veya koagulopati olması (INR> 1.5), sarllık veya koagulopati olmayanlarda ise ALT veya AST'nin normalin üst sınırını (NÜS) 5 kat, ALP'ın NÜS'nı 2 kat geçen yük-sekliğe sahip olanlar çalışmaya alındı ${ }^{8}$. Hastanın bașvurusunda TH ile benzer klinik ve laboratuvar bulgulara sahip olabilmesi nedeniyle hepatit A, B, C, D, E ve otoimmun hepatit serolojileri çalışılmıştı. Hastaların devamlı veya geçici süre için kullandıkları ilaç, şifalı bitki ve uyuşturucu madde kullanımı tarih sırasıyla öğrenilerek kaydedildi. Hastaların demografik özellikleri, TH'in muhtemel etiyolojisi, klinik özellikleri, biyokimya ve tam kan değerleri, ultrasonografi sonuçları, klinik seyri prospektif olarak kaydedildi. Gebeler, 16 yaş altında olanlar, alkol bağımlılığı olan-lar (kadınlar için 20 gr /gün, erkekler için 30 gr/gün), kronik hepatit B, C ve D tanılı hastalar ve radyolojik olarak biliyer obstruksiyon bulguları olan hastalar çalışmaya dahil edilmedi.

ALT ve ALP değerleri kendi NÜS'larına bölünerek bir katsayı bulunduktan sonra ALT katsayısının ALP katsayısına bölünerek elde edilen $\mathrm{R}$ değerine ( $>5$ ise hepatoselüler tip, $<2$ ise kolestatik tip, $>2$ ve $<5$ ise miks tip) göre karaciğer hasarlanma tipi belirlendi ${ }^{9}$.

Hastaneye yatışları esnasında tüm hastalardan imzalı bilgilendirilmiş onam formu alınmıștır.

İstatistiksel Analiz

İstatistiksel analizler SPSS 15.0 for Windows (SPSS Inc., Chicago, IL, ABD) paket programı kullanılarak yapıldı. Verilerin dağılımı
Kolmogorov Smirnov testi kullanılarak değerlendirildi. Sürekli değişkenlere ait tanımlayıcı istatistikler ortalama ve standart sapma (SD) değerleri ile gösterildi. Çarpraz tablolarm analizinde Yates düzeltmeli ve Pearson ki-kare testi kullanıldı. İki grup ortalama değerlerinin karşılaştırılmasında Student's t-testi kullanıldı. Hipotezler çift yönlü olup, $\mathrm{p}<0,05$ ise istatistiksel olarak anlaml sonuç kabul edildi.

\section{BULGULAR}

$\mathrm{Bu}$ çalışmaya yaş ortalaması $41 \pm 16$ yıl (aralık: 17-78) olan toplam 56 hasta (34 kadın, 22 erkek) alındı. Hastalar etiyolojik olarak ilaç, bitkisel ürün ve uyuşturucu madde kullanan şeklinde üç gruba ayrıldı. Grupların yaş ortalamaları; ilaç grubunda 45 yaş (aralık: 1978), bitkisel ürün grubunda 47 yaş (aralık 1773) ve uyușturucu madde grubunda 21 yaș (aralık: 17-28) idi. Uyușturucu madde grubunun yaş ortalamasının hem ilaç hem de bitkisel ürün grubuna kıyasla anlamlı derecede küçük olduğu saptandı (sırasıyla $p=0.013$ ve $\mathrm{p}=0.021$ ). Hastaların demografik, klinik ve laboratuvar özellikleri Tablo 1'de gösterilmiștir. Hastaların 4'ünde diyabetes mellitus 3'ünde bağımlılık göstermeyen alkol kullanım öyküsü mevcuttu. Hastalarımızın başvurularındaki serum biyokimya değerleri (ortalama \pm SD) AST: $799 \pm 533$ U/L; ALT :1135 \pm 819 U/L; GGT: $250 \pm 162$ U/L; ALP: $216 \pm 230$ U/L; T. Bilirubin: $5.9 \pm 6.1 \mathrm{mg} / \mathrm{dl}$; INR: $1.15 \pm$ 0.32 olarak saptandi. Hastalarm eozinofil sayıları $223 \pm 127 / \mu \mathrm{L}$ olarak saptanmış olup hiçbir hastamızda belirgin eozinofili gözlenmedi. En çok hepatosellüler tipte (\%87.5, 48 hasta) kara-ciğer hasarlanması gözlendi. Bunu miks (5 hasta) ve kolestatik tipte (2 hasta) hasarlanma izledi. Hastaların \%37'sinde başvuru sırasında sarılık mevcuttu. Hastaların INR ortalaması $1.15 \pm 0.32$ olup başvuru sırasinda sadece 4 hastada (\%7) INR $>1.5$ idi. 
Tablo 1. Toksik hepatit hastalarımızın demografik, klinik ve laboratuar özellikleri.

\begin{tabular}{|c|c|}
\hline & Toplam hasta $(n=56)$ \\
\hline Yaş, ortalama $\pm S D$ & $41 \pm 16$ \\
\hline 60 yaş üstü & $\% 14$ \\
\hline 30 yaş altı & $\% 31$ \\
\hline Kadın, n (\%) & $3(\% 61)$ \\
\hline Vücut kitle İndeksi, ortalama \pm SD & $25.4 \pm 3.4$ \\
\hline Alkol kullanımı & $\% 5,6$ \\
\hline Diyabetes Mellitus (\%) & $\% 7,5$ \\
\hline $\operatorname{ALT}(\mathrm{U} / \mathrm{L})$ (ortalama $\pm \mathrm{SD}$ ) & $1135 \pm 819$ \\
\hline $\operatorname{ALP}(\mathrm{U} / \mathrm{L})$ (ortalama $\pm \mathrm{SD})$ & $216 \pm 230$ \\
\hline Total bilurubin $(\mathrm{mg} / \mathrm{dL}$ ) (ortalama $\pm \mathrm{SD}$ ) & $5.9 \pm 6.1$ \\
\hline INR (ortalama \pm SD) & $1.15 \pm 0.32$ \\
\hline \multicolumn{2}{|l|}{ Karaciğer hasarlanma tipi, n (\%) } \\
\hline Hepatoselüler & $49(\% 87,5)$ \\
\hline Kolestatik & $2(\% 3,5)$ \\
\hline Miks & $5(\% 9)$ \\
\hline Eozinofil sayısı/ $\mu L$, ortalama $\pm S D$, (min-maks) & $223 \pm 127(18-512)$ \\
\hline \multicolumn{2}{|l|}{ Muhtemel etiyolojik ajan } \\
\hline İlaç & $31(\% 55,6)$ \\
\hline Bitkisel madde & $11(\% 20,4)$ \\
\hline Uyuş̧turucu madde & $6(\% 9,3)$ \\
\hline Karıșık & $8(\% 14,8)$ \\
\hline
\end{tabular}


Tablo 2. Toksik hepatite en s1k neden olan ajanlar.

\begin{tabular}{|c|c|c|c|}
\hline $\begin{array}{c}\text { Sıklık } \\
\text { sıralaması }\end{array}$ & $\begin{array}{l}\text { İlaçlar } \\
\text { (n) }\end{array}$ & $\begin{array}{l}\text { Bitkisel ürünler } \\
\text { (n) }\end{array}$ & $\begin{array}{l}\text { Uyuşturucu maddeler } \\
\text { (n) }\end{array}$ \\
\hline 1 & Amoksisilin-klavulanik asit (6) & $\begin{array}{l}\text { Lavanta çayı (Lavendula officinalis) (2), Meryem otu } \\
\text { (Geum urbanum) (2), Atom çayı (2) }\end{array}$ & Ekstazi (5) \\
\hline 2 & Ornidazol (4) & $\begin{array}{l}\text { Hardal otu (Mustard greens), Gergedan boynuzu, } \\
\text { Palamut çayı, Nazo çay, Yarpuz otu (Mentha } \\
\text { pulegium), , Karabaş otu (Lavandula stoechas), } \\
\text { Çörek otu (Nigella sativa), Pancar otu }\end{array}$ & Esrar + LSD (1) \\
\hline 3 & $\begin{array}{l}\text { Albendazol (3), Diklofenak (3), } \\
\text { Azatiopurin (3) }\end{array}$ & & \\
\hline 4 & $\begin{array}{l}\text { Sefuroksim aksetil (2), } \\
\text { Klaritromisin (2), Dekstraprofen } \\
\text { (2), Siproteron+Etinil estradiol } \\
\text { (2), Fenitoin (2), Fenofibrat (2) }\end{array}$ & & \\
\hline
\end{tabular}

Not: Bazı ilaçlar aynı hasta tarafından birlikte alınmış olsa da etiyolojik ajan olarak birlikte kaydedilmiştir.

Hastaların 31'inde $(\% 55,6)$ ilaçlar, 11'inde $(\% 20,4)$ bitkisel maddeler, 6'inda $(\% 9,3)$ narkotik madde ve 8 'inde $(\% 14,8)$ bitkisel madde, ilaç ve narkotik kullanımına bağlı TH gelişimi saptandı. İlaç grubunda 30 farklı ajanın, bitkisel madde grubunda 12 farklı ürünün, uyuşturucu grubunda 3 farklı maddenin kullanıldığı görüldü. Yedi hastada ilaç ve bitkisel maddeleri, bir has-tada ilaç ve uyuşturucu maddenin aynı anda kullanıldığı saptandı. İlaç grubundaki 14 (\%45) hastanın birden fazla ilacı birlikte kullandıkları saptandı. Muhtemel ilaçlar grup olarak sıralandığında antibiyotikler (14 hasta), nonsteroid antienflamatuvarlar (5 hasta) ve antiepileptikler (4 hasta) ilk üç sırayı almaktaydı. En sık karşılaşılan (6 hastada) etiyolojik ajan ise amoksisilin-klavulanik asit idi. En sık karşılaştığımız TH yapan muhtemel ajanlar gruplara göre Tablo 2'de gösterilmiștir. Toksik hepatit etiyolojileri yaş ve cinsiyet açısından değerlendirildiğinde narkotik madde grubunda istatsitiksel anlamlı farklılık saptandı. Otuz yaș altı (RR:1.545, \%95 CI:1.08-2.19, $\mathrm{p}<0.001$ ) ve erkek cinsiyet (RR:11.0, \%95 CI:1.1-102.5, $\mathrm{p}=0.013$ ) narkotik madde etiyolojisi için risk faktörleri olarak saptandı.
Hastaların hiçbirisinde (nakil ünitesi olan merkeze sevk edilen bir hastamız dahil) karaciğer transplantasyonu gerekmedi. Hiçbir hastamızda hastane izlemleri boyunca karaciğer veya karaciğer dışı sebeplere bağlı ölüm gözlenmedi. Biri meme kanserli kadın, diğeri kalp yetmezlikli erkek olan iki hastamız taburculuk sonrası, sirasıyla, ikinci ve dördüncü aylarda öldüğü tespit edilmiştir.

\section{TARTIŞMA}

Yaklaşık iki yllık sürede, 56 TH vakasının değerlendirildiği bu çalışmada, TH'lerin bölgemiz-deki en sık nedeni ilaçlardır. İkinci sırada yer alan bitkisel ürün kullanımının (tek başına ve ilaçlarla birlikte) TH'lerin üçte birinden sorumlu olduğu ortaya konmuștur. Ayrıca genç hastalardaki (otuz yaş altı) TH'in önde gelen sebebinin uyuşturucu maddeler olduğu görülmüștür.

Dünya genelinde TH'in en sık nedeni ilaçlar, bunlar içinde de antibiyotikler olduğu gösterilmiştir8,10-12 Bulgularımız önceki çalışma sonuçlarıyla tutarlı olarak antibiyotiklerin en sık karşılaşılan ilaçlar olduğunu gösterdi. Benzer şekilde antibiyotikler içinde de en sık karşılaşılan amoksisilin-klavulanik asit 8,10-12 
çalışmamızda da birinci sırada yer almaktaydı. Antibiyotiklerin, TH'e neden bu kadar yüksek bir eğilime sahip olduğu sorusunun yanıtı açık değildir. Fakat toplumda antibiyotiklerin daha yüksek oranda kullanılması veya altta yatan enfeksiyon ve inflamasyon gibi biyolojik nedenlerin, artmış yatkınlığa sebep olabileceği düşünülmektedir ${ }^{13}$.

Toksik hepatit vakalarında birden fazla muhtemel hepatotoksik ajanın birarada kullanımı mevcut olabilmektedir. Birden fazla hepatotoksik ajanın kullanım oranları \%9-20 arasında bildirilmiştir ${ }^{8,10}$. Bizim çalışmamızda bu oran \%45 ile literatürde belirtilen oranlara klyasla oldukça yüksek bulunmuştur . Bu durum TH etiyolojisinde en çok karşılaşılan antibiyotik ve ağrı kesici gibi ilaçların yakın zamana kadar ülkemizde reçetesiz ulaşılmasıyla açıklanabilir.

Çalışmamızda TH etiyolojisinde uyuşturucu madde kullananları yaklaşık \%10 oranında olması nedeniyle ilaç ve bitkisel ürün grubundan ayrı olarak ele aldık. Bu grupta en sık karşılaştığımız madde ekstazi olarak bilinen 3,4-metilendioksimetamfetamin (MDMA) idi. MDMA yapısal ve farmakolojik olarak amfetamine benzeyen sentetik bir bileşiktir ${ }^{14}$. MDMA'nın çoğunluğu değişmeden idrarla atılmakla birlikte kalan \%25'i primer olarak karaciğerde sitokrom P450 aracılığıyla metabolize olmaktadır ${ }^{15}$. Öfke, uyanıklık, yakınlı, cinsel uyarılma ve disinhibisyon duygularını ortaya çıkardığından dolayı MDMA, özellikle genç yetişkinler arasında yaygın kullanılan, bağımlılık yapıcı bir ilaç haline gelmiştir ${ }^{16}$. Ekstazi kullanımı sonucunda bazıları kara-ciğer nakline giden $\mathrm{TH}$ vaka sunumları bildirilmiştir ${ }^{17,18}$. Bu vakaların tümü genç yetişkinlerden oluşmaktadır. Çalışmamızda subgrup analizinde TH'liler arasında uyuşturucu madde kullanımının sorumlu etiyolojik ajan olma riskinin otuz yaș altı (RR:1.545, \%95 CI:1.08-2.19, p<0.001) ve erkeklerde (RR:11.0, \%95 CI:1.1-102.5, $\mathrm{p}=0.013$ ) istatistiksel olarak anlaml derecede olduğunu saptadık.

Dünya genelinde hem sağlıklı hem de belli rahatsızlığa sahip kişiler arasında bitkisel ve diyet ürünlerinin kullanımı yaygınlașmaktadır. Reçetesiz kullanılan bu ürünler $\mathrm{TH}^{\prime}$ in önemli nedenlerinden biri haline gelmektedir ${ }^{19,20}$. Amerika Birleşik Devletleri nüfusunun yaklaşı \%40'nın alternatif tedavi yöntemlerini, en çok bitkisel ve diyet ürünlerini, kullandığı tahmin edilmektedir. Bu ürünlerin önde gelen kullanım endikasyonlarl; kilo verme, vücut geliștirme, menapozal semptomları giderme, hazımsızlık ve kabızlık gibi sindirim semptomları, karaciğer hastalıkları, baş ağrısı ve migren gibi nörolojik yakınmaları gidermeye yöneliktir ${ }^{21}$. Ülkemizde bu ürünlerin yaygın kullanımı tahmin edilmekle birlikte yeterli veri bulunmamaktadır. Çalışmamızda TH nedenleri arasında ikinci sırada yer alan bitkisel ürünler hastaların üçte birinin etiyolojisinden sorumlu ajanlar olarak saptanmıştır. $\mathrm{Bu}$ konunun giderek üstünde durulması gereken bir halk sağlığı sorunu olduğunu desteklemektedir.

Birçok ilacın birden fazla karaciğer hasarlanma tipine (hepatoselüler, kolestatik veya miks) sebep olabildiği bilinmektedir. ${ }^{22}$ Bununla birilikte büyük vaka serilerinde en baskın olan tipin hepatoselüler karaciğer hasarı olduğu gösterilmiștir ${ }^{8,10,23-25}$. Literatürle uyumlu olarak hastalarımızın $\% 87,5$ 'unda karaciğer hasarlanmasının önde gelen tipi hepatoselüler hasralanma olarak saptanmıştır.

İlaca bağlı hasarlanmada çoğunlukla idiyosenkratik mekanizmalar sorumludur. Bunun dışında allerjinin klasik klinik veya laboratuvar özelliklerini (ateș, döküntü, eozinofili, sitopeni) gösteren vakalarda hipersensitivite veya immunlojik mekanizmalar sorumlu tutulmaktadır ${ }^{10}$. Eş zamanlı ciddi deri reaksiyonlariyla (Steven Johson Sendromu, Toksik Epidermal Nekroliz) seyreden $\mathrm{TH}$ vakalarında prognozun kötü olacağı öngörülmektedir. Yakın zamanda yayınlanmış 
geniş TH serisinde, cilt tutulumu olan vakalarda $\% 45$ gibi yüksek mortalite oranları bildirilmiştir ${ }^{8}$. Ciddi deri reaksiyonlarının yanı sıra ileri yaș, kadın cinsiyet, hepatoselüler tipte hasarlanma, altta yatan karaciğer hastalığının varlığ

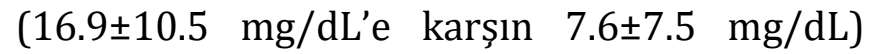
diğer prognostik mortalite göstergelerdir ${ }^{8,10}$. Toksik hepatit seyrinde \%4-5 oranında karaciğer nakli ve \%2-6 oranında mortalite görülmektedir ${ }^{8,10}$. Sunduğumuz bu çalışmada hiçbir hastamızda kliniğimizdeki yatış süresi boyunca ölüm gözlenmedi ve karaciğer transplantasyonu yapılması gerekmedi. Transplantasyon ünitemizin olmaması nedeniyle karaciğer yetmezlikli vakaların hastanemize refere edilememiş olması bunu etkileyen önemli bir faktör olabilir. Ayrıca hastalarımızda altta yatan karaciğer hastalığının olmaması, cilt tutulumunun gözlenmemesi, bilirubin ve INR değerlerinin diğer serilerdekilere kıyasla daha düşük olması çalışmamızdaki iyi seyir sonuçlarını açlklayabilecek diğer faktörlerdir.

Bölgemiz için önemli verileri elde etmiş olmakla birlikte çalışmamızın en önemli kısıtlayıcı yönü tek merkezli olması ve karaciğer fonksiyon testlerinde belirgin yükseklik olmayan, ayaktan takip edilen hastaların çalışmaya dahil edilmemesi nedeniyle az sayıda hastaya sahip olmasıdır. Hastalarımızın taburculuk sonrası kontrol-tam iyileşme verilerinin olmaması çalışmamızın diğer kısıtlayıcı yönüdür. İlaca bağlı $\mathrm{KC}$ hasarıyla ilgili ulusal bir ağ kurulmasının hekimler arasında farmako-epidemiyolojik bilinçlenme ve ilaca bağlı karaciğer hasarı farkındalığını artırmaya katkı sağlayacaktır ${ }^{10}$. Vaka raporlarının seçici ve gerçek hayatta görülenden daha az bildirim yapması nedeniyle bu çalışmalar hepatotoksisite verilerini daha iyi yansıtmaktadır ${ }^{10}$. Bu nedenle ülkemizde yapılacak çok merkezli ve geniş katılımlı TH çalışmaları yol gösterici olacaktır.
Sonuç olarak; bölgemizde ilaçlar $\mathrm{TH}$ etiyolojisinde ilk sırada yer alan grup olmasına rağmen bitkisel ürünler de azımsanamayacak oranlarda sorumlu bulunmuştur. Çalışmamızda amoksisilin-klavulanik asit TH'e en çok neden olan ilaç olarak saptanmıştır. Bölgemizde genç yaştaki erkeklerde, TH etiyolojisinde uyuşturucu madde kullanımının ilk sırada yeraldığı gösterilmiştir.

$\mathrm{Bu}$ makalenin bir kismı 33. Ulusal Gastroenteroloji kongresinde poster bildiri olarak kabul edilmiştir.

Çıkar Çatışması Beyanı: Yazarlar çıkar çatışması olmadığını bildirmişlerdir.

Finansal Destek: Bu çalışma her hangi bir fon tarafından desteklenmemiştir.

Declaration of Conflicting Interests: The authors declare that they have no conflict of interest.

Financial Disclosure: No financial support was received.

\section{KAYNAKLAR}

1. Devarbhavi H, Bonkovsky HL, Russo M, Chalasani N. Drug-Induced Liver Injury. In: Sanyal A J, Boyer TD, Lindor KD, Terrault NA. editors. Zakim and Boyer's Hepatology: A Textbook of Liver Disease . Seventh Edition. Elsevier: Philadelphia; 2018. P 844-890.

2. Danan G, Teschke R. RUCAM in Drug and Herb Induced Liver Injury: The Update.Int J Mol Sci. 2015 Dec 24; 17(1). pii: E14. doi: 10.3390/ijms17010014.

3. Teschke, R, Eickhoff, A. Herbal hepatotoxicity in traditional and modern medicine: Actual key issues and new encouraging steps. Front. Pharmacol. 2015; 6: 140.

4. Bell LN, Chalasani N. Epidemiology of idiosyncratic drug-induced liver injury. Semin Liver Dis 2009; 29:337.

5. Chalasani N, Fontana RJ, Bonkovsky HL, et al. Causes, clinical features, and outcomes from a prospective study of drug-induced liver injury in the United States. Gastroenterology 2008; 135:1924-34. doi: 10.1053/j.gastro.2008; 09:011. 
6. Zimmerman HJ. Drug-induced liver disease. Clin Liver Dis 2000; 4:73-96.

7. Ostapowicz G, Fontana RJ, Schiødt FV, et al. Results of a prospective study of acute liver failure at 17 tertiary care centers in the United States. Ann Intern Med 2002; 137:947.

8. Chalasani N, Bonkovsky HL, Fontana R, et al., United States Drug Induced Liver Injury Network. Features and Outcomes of 899 Patients With Drug-Induced Liver Injury: The DILIN Prospective Study. Gastroenterology. 2015; 148:1340-52. doi: 10.1053/j.gastro.2015; 03:006.

9. Benichou C. Criteria of drug-induced liver disorders. Report of an international consensus meeting. J Hepatol 1990; 11:272-6.

10. Andrade RJ, Lucena MI, Fernandez MC, et al. Drug induced liver injury: an analysis of 461 incidences submitted to the Spanish registry over a 10-year period. Gastroenterology 2005; 129:512-21.

11. De Valle MB, Klinteberg VA, Alem N, et al. Drug induced liver injury in a Swedish Uni-versity Hospital out-patient hepatology clinic. Aliment Pharmacol Ther 2006;24:1187-95.

12. Pillans PI. Drug associated hepatic reactions in New Zealand: 21 years experience. N Z Med J 1996; 109:315-9.

13. Ganey PE, Luyendyk JP, Maddox JF, et al. Adverse hepatic drug reactions: inflammatory episodes as consequence and contributor. Chem Biol Interact 2004; 150:35-51.

14. Christophersen AS. Amphetamine designer drugs--an overviewand epidemiology. Toxicol-Lett. 2000;112113:127-131.

15. Wu D, Otton SV, Inaba $\mathrm{T}$, et al. Interactions of amphetamine analogs with human liver CYP2D6. BiochemPharmacol.1997; 53:1605-12.

16. Arria AM, Yacoubian GS Jr, Fost E, Wish ED. The pediatric forum: Ecstasy use among club rave attendees. Arch Pediatr Adolesc Med. 2002; 156: 295-6.
17. Guneysel O, Onur OE, Akoglu H, Denizbasi A. Ecstasyinduced recurrent toxic hepatitis in a young adult. Curr Ther Res Clin Exp. 2008 Jun; 69:260-5. doi: 10.1016/j.curtheres.2008.06.001.

18. Atayan Y, Çağın YF, Erdoğan MA, Harputluoglu MM, Bilgic Y. Ecstasy induced acute hepatic failure. Case reports. Acta Gastroenterol Belg. 2015 Jan-Mar; 78:535.

19. Seeff LB. Herbal hepatotoxicity. Clin Liver Dis 2007; 11:577-96.

20. Strader DB, Seeff LB. Hepatotoxicity of herbal preparation. Chapter 37. In: Boyer TD, Wright TL, Manns MP, eds. Zakim and Boyer's hepatology, a textbook of liver disease. 5th ed. Philadelphia, PA:Saunders-Elsevier, 2006: 551-60.

21. National Institutes of Health (NIH) and LiverTox: Agents Included in LiverTox by Drug Class. Available online:

https://livertox.nlm.nih.gov//Herbals_and_Dietary_Sup plements.htm (accessed on 17 Octoberber 2017).

22. Andrade RJ, Lucena MI. Drug-induced hepatotoxicity. N Engl J Med 2003; 349:1974-6.

23. Sgro C, Clinard F, Ouazir K, et al. Incidence of druginduced hepatic injuries: a French population-based study. Hepatology 2002; 36: 451-5.

24. Ibáñez L, Pérez E, Vidal X, Laporte JR, the Grup d'Estudi Multi- centric d'Hepatotoxicitat Aguda de Barcelona (GEMHAB). Pro- spective surveillance of acute serious liver disease unre-lated to infectious, obstructive, or metabolic diseases: epidemiological and clinical features, and exposure to drugs. J Hepatol 2002; 37:592-600.

25. Friis H, Andreasen PB. Drug-induced hepatic injury: an analysis of 1100 cases reported to the Danish Committee on Adverse Drug Reactions between 1978 and 1987. J Intern Med 1992; 232: 133-8. 